\title{
UMA PÁGINA FEMININA: ESCRITOS PARA A EDUCAÇÃO DAS MULHERES PARAIBANAS (DÉCADA DE 1930)
}

\author{
Maria Lúcia da Silva Nunes ${ }^{1}$ \\ Charliton José dos Santos Machado ${ }^{2}$
}

\section{RESUMO}

Este artigo tem como objetivo sugerir uma classificação temática dos textos da Página Feminina, da Associação Paraibana Pelo Progresso Feminino (APPF), no jornal A União $\mathrm{PB}$, destacando o caráter educativo desse espaço de escrita feminina. O aporte teóricometodológico da Nova História Cultural subsidiou a leitura empreendida porque propicia a liberdade de considerar fontes como o jornal diário e alçar a sujeito da história a mulher, elementos estes esquecidos pela historiografia durante grande parte da história da humanidade. Com essa concepção, e tendo como processo metodológico a pesquisa bibliográfica, toma-se para fonte textos publicados no jornal citado, escritos por mulheres associadas à APPF, na década de 1930, período em que a referida associação atuou de modo mais intenso na divulgação das lutas femininas. A leitura realizada permite afirmar que a APPF usou o espaço no órgão oficial da imprensa paraibana tanto na propagação de suas ações quanto no fomento da educação das mulheres paraibanas, no momento em que as mesmas reivindicavam direitos e buscavam visibilidade; também exerceu uma função significativa, ao incentivar a prática da escrita por mulheres e ao divulgar essa produção. Palavras-chave: Mulher; Imprensa; Educação; Escrita.

\section{A FEMALE PAGE: WRITINGS FOR EDUCATION OF PARAIBAN WOMEN (1930)}

\begin{abstract}
This article has as purpose to suggest a thematic classification of the texts from the Female Page, of the Feminine Progress Paraiban Association (APPF), in the newspaper A União $\mathrm{PB}$, emphasizing the educational nature of this spot of female writing. The theoreticalmethodological basis of the New Cultural History subsidized the undertaken reading because it provides the freedom to consider sources as the diary newspaper and to hoist the woman as the subject of the history, elements forgotten by the historiography during large part of the human history. With this conception, and having the bibliographic research as methodological process, are taken as source the texts published in the newspaper in question, written by women associated to the APPF, during the 1930s, period in which the referred association acted more intensively on the sharing of the women's struggles. The reading that took place allows to assert that the APPF used the spot on the paraiban media's official body for both the propagation of its acts and the fomentation of the paraiban women education, in the moment they claimed for rights and seek visibility; also executed a meaningful function, inciting the practice of writing by women and sharing this production.
\end{abstract}

Keywords: Woman; Media; Education; Writing. 
Este artigo, vinculado aos projetos de pesquisa Quando as mulheres escrevem: textos sobre educação na imprensa da Paraíba (décadas de 1920 e 1930) e Educação e Educadoras na Paraíba do século XX: práticas, leituras e representações, em andamento, junto ao grupo HISTEDBR-GT/PB, tem como objetivo sugerir uma classificação temática dos textos da Página Feminina, da Associação Paraibana Pelo Progresso Feminino (APPF), no jornal A União - PB, destacando o caráter educativo desse espaço de escrita feminina. Para tanto, fizemos uso da pesquisa bibliográfica estabelecendo um diálogo com os referenciais da Nova História Cultural.

Ler os textos escritos por mulheres paraibanas na década de 1930, tentando entender seus sentidos e suas funções naquele momento, voltar o olhar para aquela configuração, significa assumir responsabilidade, enquanto historiadores da educação, de trazer à tona elementos que apontem para o uso que as mulheres iam gradativamente fazendo da escrita, como um modo de se tornarem sujeitos da história e escreverem as suas próprias. Mas nesse fazer, precisamos estar atentos ao suporte no qual esses textos se materializam, concordando com Chartier (2002, p. 61) quando alerta:

Os textos não existem fora dos suportes matérias (sejam eles quais forem) de que são veículos. Contra a abstração dos textos, é preciso lembrar que as formas que permitem sua leitura, sua audição ou sua visão participam profundamente da construção de seus significados.

Temos consciência disto! Tanto que organizamos este artigo procurando destacar algumas questões que estão entrelaçadas à produção escrita publicizada na Página Feminina; questões que podem colaborar na compreensão do papel que desempenhou tal espaço, como: a mulher paraibana e a configuração de 1930, a imprensa e a luta das mulheres, a Associação Paraibana pelo Progresso Feminino e escritos de/para formação da mulher.

\section{A mulher paraibana e a configuração de 1930}

A década de 1930 corporifica de modo mais intenso as transformações comportamentais e a adoção de novos hábitos, ou seja, as mudanças iniciadas com a Proclamação da República consolidam-se. A emergência de novos espaços públicos, representativa desse período, era sinônimo não só da expansão urbana como também da crescente emancipação da mulher, transitando entre o espaço doméstico, privado, e o público, das ruas, dos passeios. Essas novidades, no entanto, não eram vistas com bons olhos pela sociedade patriarcal: o acesso ao mercado de trabalho para as mulheres restringia-se a atividades relacionadas às prendas domésticas e ao magistério. Atividades que se aproximassem mais do perfil da mulher e das atribuições tidas como "inerentes" e naturais, como cuidar, acompanhar, educar, fazer trabalhos manuais. Na verdade, o que toda família almejava para suas filhas era um bom casamento.

Dessa forma, a abertura dos novos espaços, o trânsito da casa para a rua, a frequência a lugares antes proibidos, a possibilidade de uma vida profissional, eram processos conquistados gradativamente, não sem alguns obstáculos. Sair à rua, por exemplo, exigia uma companhia adequada: a mãe, a irmã, o irmão, o pai, uma prima, o marido, os filhos pequenos. Mulher sozinha na rua não era vista com bons olhos, embora, segundo Dauphin (1999), referindo-se a outra realidade que não à brasileira, a designação 
"mulher só" já existia no século XIX e, mesmo que esse fato tivesse explicações sociais e econômicas, não livrava a mulher que assim se apresentasse de ser tida como o "antimodelo da mulher ideal".

A expressão de insatisfação da mulher diante da inexistência de um lugar social próprio, da visão pejorativa de que muitas vezes era vítima, da falta de representação no âmbito político, da não relevância de sua participação na economia, o desejo de liberdade e de igualdade com os homens, tudo isto era visto como uma ameaça à ordem familiar e, consequentemente, a sociedade estava em perigo. (NUNES, 2007, p.284)

Para tratar da inserção da mulher paraibana na sociedade da época, vejamos, em breves linhas a situação do estado da Paraíba. Na década citada, ocupou lugar de destaque no contexto nacional, visto que o Estado estava diretamente envolvido na composição do Governo Federal, pois como vice-presidente na chapa com Getúlio Vargas estava João Pessoa, situação essa fruto de um arranjo que se denominou de Aliança Liberal, sustentada pela composição entre Rio Grande do Sul, Minas Gerais e Paraíba, após a falência do modelo de reciprocidade política que predominou na Primeira República, denominado café com leite.

O modelo político defendido pela Aliança Liberal ganhava a adesão de vários segmentos urbanos da sociedade, pelo país afora, entre aqueles insatisfeitos com as oligarquias rurais, mas também como decorrência dos ideais reformistas pregados pelos liberais. (MACHADO; NUNES, 2007).

Dentre os grupos urbanos, na Paraíba, que manifestaram seu apoio às propostas liberalistas, destaca-se o das mulheres educadoras, que passaram a integrar os comitês femininos pró-Aliança Liberal. É o que informa o jornal A União em notícia veiculada no dia 25 de janeiro de 1930, logo na primeira página, sob o título A brilhante cooperação feminina em prol da Aliança Liberal: "O comitê 'Clara Camarão', de Campina Grande, realizou uma excursão de propaganda da Aliança Liberal, a 19 do corrente, indo até Esperança e São Sebastião, onde realizaram meeting em meio ao maior entusiasmo".

Para Mello (1979), essa participação das mulheres atendia aos apelos feministas de Carlos Dias Fernandes e José Américo de Almeida e tinha como principais entusiastas da Aliança Liberal as alunas da Escola Normal. Segundo Aguiar (2005, p.19):

Elas estavam na maioria das vezes à frente das passeatas e meetings, como se dizia na época. Fardadas de azul e branco entre seus 14 e 20 anos, as normalistas bem simbolizavam o total apoio do povo à reforma e renovação empreendidas no Governo pelo estadista conterrâneo.

Confirmação desse entusiasmo liberalista das normalistas está registrada nas páginas d'A União, em 16 de maio de 1930 (p.5):

Destaca-se, sobretudo, nessa irresistível corrente de sympathia, a contribuição espontânea e comovedora da mulher parahybana. Era Ella que ante-hontem ia, representada em todas as allumnas da Escola Normal, levar ao presidente algumas centenas de balas para a campanha.

Como se vê, o clima no Estado não estava tranquilo e culminou com o assassinato de João Pessoa, em 26 de julho desse mesmo ano, por seu opositor João Dantas, na 
Confeitaria da Glória, em Recife. Fato este que funcionou como estopim para o acirramento das manifestações aliancistas e para a revolução propriamente dita.

Morto João Pessoa, as manifestações de solidariedade empreendidas pelos seus correligionários passa a ocupar espaço significativo nas páginas d'A União, órgão da imprensa oficial do Estado. As mulheres continuam saindo às ruas, organizando passeatas, participando de solenidades, agora não apenas de caráter liberalista, mas também em homenagem ao político morto, que passa a ser reverenciado como mártir e herói. É o que estampa notícia publicada em 20 de novembro de 1930 (p.1):

\begin{abstract}
Mais uma homenagem da mulher parahybana a João Pessoa. Em toda a campanha política que vimos de vencer a mulher parahybana teve papel saliente. Vivo João Pessoa, o grande martyr na nova república, não lhe faltou um só instante a solidariedade dos mais destacados elementos femininos de nossa terra. Trucidado miseravelmente, na suposição de que, com sua morte, ficariam vencidos todos os óbices e entrega da Parahyba ao Perrepismo criminoso, estamos vendo que as reservas de affecto, de admiração, de dedicação das bravas, determinadas pessoenses são inexgotáveis. A todas as homenagens prestadas a memória do inolvidável brasileiro, mesmo as que significavam gestos de vindicta contra os seus ferrenhos adversários, associou-se vehemente efficientemente a mulher parahybana. Bastemos relembrar aqui a ação das nossas normalistas, que se entregaram dias a fio a manifestações de desaggravo ao morto inmortal, com risco até da própria vida. [...] Uma comissão de inteligentes e graciosas alumnas da Escola Normal tomou a si o encargo de offerecera exc.viúva Maria Luiza Pessoa o grande retrato a óleo, corpo inteiro que acaba de executar o ilustre Frederico Falcão e que esteve até pouco tempo em exposição na Escola Normal.
\end{abstract}

Sem esquecer que havia uma comunhão no ideário político entre o jornal e as mulheres, ficou registrado que as mesmas contavam com um favorecimento na divulgação de suas ações e esse espaço foi aproveitado para publicização de suas ideias, no momento em que criaram uma associação feminina. Essa relação harmoniosa nem sempre foi a tônica entre as mulheres e a imprensa. É o que discutimos brevemente no tópico seguinte.

\title{
A imprensa e a luta das mulheres
}

Quando as mulheres começam a lutar pelos seus direitos, a tornarem públicas suas opiniões, a demandarem uma participação nas deliberações nos variados campos que dão forma ao país, a adentrarem espaços distintos no mercado de trabalho, a examinarem as relações homem-mulher, os diversos setores da sociedade começam a expressar reações adversas. A imprensa, como instrumento de divulgação de informações e como formadora de opinião, corrobora as posições das instituições sociais responsáveis pela determinação de códigos de comportamento das pessoas, como Igreja e Estado, entre outras. A sociedade utiliza-se de várias estratégias para fazer as mulheres desistirem de lutar por seus direitos e influenciar as pessoas a reagirem contra essa luta. Nesse âmbito, a performance da imprensa é significativa, porque busca atacar a mulher em aspectos caros a sua autoestima, como a beleza, a aparência física, por exemplo. Viam-se comumente nos jornais caricaturas de mulheres, cujo destaque era atribuir feiura ou características 
masculinizantes àquelas que demonstravam interesse em participar das decisões políticas e que se envolviam nos movimentos em prol da liberdade das mulheres e da conquista dos direitos. Havia uma equação que se explicava assim: essa mulher que ousava querer conquistar mais espaço na sociedade, certamente era feia, por isso não arranjava casamento, e, consequentemente, descontente e frustrada, via na luta por direitos uma forma de vingar-se dos homens. Dito de outro modo, ela só se envolvia nessa discussão porque não fora capaz - já que não possui os atributos necessários - de conseguir um marido. Soihet destaca esse tratamento agressivo da imprensa (2000, p. 109):

Na imprensa a situação não se afigurava mais favorável ao feminismo. Ao longo do tempo, este vinha sendo objeto de grosseiras caricaturas em crônicas e charges, nas quais buscava passar mensagem do terror e do grotesco que representaria a participação das mulheres em esferas consideradas próprias dos homens.

Como justificativa para censurar o comportamento combativo feminino apontavam-se aspectos distintos: desordem familiar, inaptidão dos homens para cuidarem dos filhos e de atividades domésticas, dimensão sagrada das mulheres através da maternidade, incapacidade intelectual da mulher para a esfera pública, masculinização da mulher que exige seus direitos, entre outros. Com isto, apontava-se para a possibilidade de um caos na família e na sociedade, caso a mulher continuasse a exigir uma nova estrutura familiar e social.

Ainda refletindo sobre a forma como as mulheres eram apresentadas, Soihet (2000, p.110) realça a violência simbólica (numa referência a Bordieu, 1992) entranhada nos discursos veiculados.

[...] percebe-se um aspecto perverso nessas insinuações, o que me faz enquadrar tais colocações numa das modalidades de violência simbólica. Isto porque a reiteração da comicidade na abordagem das reivindicações das feministas tende a difundir uma imagem em voga: a do despropósito das preocupações femininas, ao contrário das masculinas.

Na Paraíba, a imprensa também desempenhava esse papel. Através de seus intelectuais, o pensamento da sociedade em relação à luta da mulher era exposto. É o que se vê nesse texto da professora Eudésia Vieira, citada por Joffily (1980, p. 4), publicado na revista Era Nova:

Temos a sufragista. É sempre uma revoltada que procura abafar seus padecimentos querendo não ser a companheira do homem mas rival ou mesmo antagonista. Merece também compaixão. Foi a infelicidade que a impeliu à extravagância de proceder para destarte sufocar o sentimento latente.

Este fragmento remete, mais uma vez, ao texto de Soihet (2000, p. 110-111), quando comenta que era comum, na época, as mulheres incorporarem o discurso dominante e atribuírem àquela que lutava por seus direitos o rótulo de frustrada, entre 
outros, terminando por enquadrá-la no antimodelo da mulher ideal.

Embora Joffily não informe o ano desse texto, é fácil localizá-lo na década de 1930, porque Eudésia publicava constantemente na Revista textos nos quais ficava clara a sua opinião contrária aos "modernismos" do comportamento feminino. Vejamos um trecho de 1932 de um texto intitulado A mulher e o Progresso, no qual Eudésia Vieira critica a liberdade da mulher:

No assedio bárbaro à moral cristã, intensificado pelo apregoamento da liberdade licenciosa, cumpre à mulher zelar o tesouro da virtude agitando alto a flâmula da fé. Seguindo a vida monástica, permanecendo virgem no século, ou contraindo esponsais, uma só deve ser sua aspiração - o aperfeiçoamento próprio e a dos que o cercam pelo culto do amor ao supremo Bem. (VIEIRA, 1932, p.4).

Mais adiante, a articulista aponta que a mulher moderna não deve se contentar mais com a situação de ignorância e de servidão a um "senhor absoluto"; o que pode parecer uma posição questionadora e em prol dos direitos da mulher, termina recuando para a ideia reinante nas instituições de então e defendida principalmente pela igreja católica: qualquer ação que venha a ser empreendida pela mulher deve ser em benefício dos outros, da família, da sociedade; caminhando ao lado do homem, sendo protegida por ele.

A mulher hodierna - tão somente esposa, já não suporta a ideia passadista do senhor absoluto, tão vulgar em outros tempos, Ela marcha par ao altar com a convicção de ser companheira do seu escolhido, tirada do seu lado, do seu coração, para ser por ele amada e protegida como ensina o apóstolo dos gentios. (VIEIRA, 1932, p.4)

O discurso de Eudésia Vieira serve para nos lembrar que em pleno período fértil à luta e ao debate pelos direitos da mulher, nem todas as mulheres estavam de acordo com o que era preceituado pelos movimentos feministas. Eudésia, paraibana, com formação superior, escritora, alinhava sua opinião às ideias da maioria das pessoas daquele contexto, da igreja, da medicina, da imprensa. Não seria este um motivo de a mesma conseguir espaço para publicar seus textos com tanta frequência nos jornais e revistas, principalmente na Imprensa, órgão sob a orientação e direção da Igreja Católica?

A moda, campo "imediatamente" relacionado à mulher era motivo de discussão na imprensa, como se vê neste trecho de A Imprensa, também retomado por Joffily (1980, p. 36):

Entre nós o decote é exibido pelas mulheres com uma semcerimônia pasmosa. As campanhas moralizadoras das toilletes não encontram a repercussão desejada nos círculos femininos da família. Consente-se que senhoras e senhoritas, até mesmo entre as que se dizem católicas com uma imoderação lamentável.

Qualquer alteração no comportamento feminino transformava-se em assunto para debate nos jornais e revistas da época. (NUNES, 2006).

A partir da década de 1930, no jornal A União, começa a ser frequente a 
publicação de textos versando sobre o feminismo, sobre os interesses femininos, sobre temas relacionados à mulher, de um modo geral. Eram textos escritos por homens e mulheres, às vezes identificados e outras não. Mas o que nos interessa aqui é destacar os textos que foram publicados na Página Feminina, do referido jornal, de autoria feminina, das mulheres que compunham a Associação Paraibana pelo Progresso Feminino (APPF).

\section{A Associação Paraibana pelo Progresso Feminino}

A exemplo do que vinha acontecendo em outros estados, desde a criação da Federação Brasileira pelo Progresso Feminino (FBPF) em 1922, embora com uma distância significativa de 11 anos, em 11 de março de 1933 instala-se a Associação Paraibana pelo Progresso Feminino na sede da Escola Normal, em João Pessoa, após a realização de duas sessões preparatórias, uma no dia seis e outra no dia treze de fevereiro daquele ano. A diretoria era composta por mulheres de destaque na sociedade paraibana pela atuação no sistema educacional local: presidente: Lylia Guedes, vice-presidente: Olivina Carneiro da Cunha, secretária: Alice de Azevedo Monteiro, oradora: Albertina Correia Lima, tesoureira: Francisca de Ascenção Cunha e, bibliotecária: Analice Caldas.

Todos os nomes que formam a diretoria atual da novel sociedade têm uma alta significação no seio do magistério e da sociedade paraibana. Nomes que são uma flâmula da vitória ganha na luta diária por um lugar de honra na vida humana. (MACHADO, 1933, p.3).

Assim como em 1930, quando as mulheres, organizadas muitas vezes em comitês ou em grupos de afinidades, como era o caso das normalistas, participavam ativamente nos acontecimentos políticos e por isso apareciam com frequência nas páginas d'A União, as sócias da APPF estarão em destaque nas páginas de tal jornal, seja como notícia, seja como autoras de textos. Da participação espontânea e aleatória, as mulheres constroem um espaço fixo nesse órgão da imprensa oficial paraibana. Para tanto, vão preparando paulatinamente essa conquista, construindo relações que compõem as redes de sociabilidade, ou, no dizer de Elias (1970), a configuração.

Logo após a fundação da Associação, dois fatos merecem destaque: o primeiro é o pedido que a direção da Associação faz ao jornal para que publique uma carta cujo teor é a preocupação em explicar-se diante da sociedade paraibana em geral, mas, principalmente diante da Igreja Católica e da ordem governamental contemporânea, sobre sua "neutralidade". É o que informa o fragmento seguinte:

Logo ao circular a notícia de nossa instalação, algumas associações católicas eram advertidas pelos seus diretores espirituais de que a Federação Brasileira pelo Progresso Feminino, com sede no Rio de Janeiro. Dirigida pela Dra. Bertha Lutz - sociedade por cuja iniciativa fora fundada a nossa, pregava idéias contrárias ao catolicismo. Ora, a nossa única intenção foi reunir a família paraibana no laço da maior fraternidade, sem impor princípios que viessem ferir melindres religiosos, políticos ou mesmo regionalistas. A Associação com suas sessenta e tanta associadas, em grande parte católicas [...] tendo como preocupação exclusiva o engrandecimento da mulher sem imposição ou restrição alguma às suas crenças que serão respeitadas de modo absoluto. 
Todas somos mulheres e é isto que nos une. (PARAÍBA, Estado da. ASSOCIAÇÃO PARAIBANA..., 5 abril de 1933, p.1).

O outro fato é que uma das primeiras atividades socioculturais organizadas pela APPF teve como objetivo homenagear o interventor Gratuliano Brito, o cônego Mathias Freire e a Imprensa. Segundo foi noticiado pelo jornal, a festa transcorreu em meio a aplausos e reconhecimentos recíprocos. O cônego falou em seu nome e no do interventor, agradecendo a homenagem, bem como enaltecendo os "relevantes serviços" que a Associação, recém criada, vinha prestando à mulher pessoense. De parte da APPF, a escritora Juanita Machado foi a representante, pronunciando um discurso laudatório que exalta a generosidade das duas autoridades referidas acima, cuja principal ação parece ter sido a cessão do espaço da Escola Normal para sediar a Associação.

$\mathrm{O}$ agradecimento feito à imprensa paraibana tem caráter bastante incisivo destacando a "grande" contribuição do jornalismo para o desenvolvimento das civilizações.

O jornalismo nós o sabemos, vale pelas idéias que propaga, pelos incentivos que espalha, pela elegância da voz, clarim da mentalidade de um povo. Sua percussão fica reboando através dos tempos, como o sinal mais nítido de uma época; ele é o marco luminoso de propaganda de todas as tentativas, é enfim o gigante de botas de sete léguas, levando o facho das civilizações por esse mundo afora. Nós, que muito devemos ao jornalismo prestigioso e inteligente de João Pessoa, pedimos aos representantes dele, aqui presentes, que transmitam aos seus jornais o "muito obrigado" profundamente sincero da Associação Feminina. (PARAÍBA, Estado da. A BRILHANTE ..., 25 de junho de 1933, p.1).

Cinco dias após essa homenagem "Uma comissão de senhoras e senhoritas da referida Associação procurou o diretor desta folha, Dr Samuel Duarte, pleiteando uma página quinzenal, para a necessária divulgação de trabalhos literários e de propaganda firmados por suas consócias, sendo imediatamente atendidas". (PARAÍBA, Estado da. ASSOCIAÇÃO PARAIBANA...30 de junho de 1933, p.1).

Embora preocupadas com as homenagens e com as justificativas de que a Associação não traria nenhum desajuste à sociedade paraibana, as socias procuravam, em seus textos, sempre deixar claro a importância e a necessidade de ser oferecida educação para a mulher, a fim de transformá-la em elemento impulsionador do progresso: "Enfim, chegamos à resolução dessa vontade de ferro - fazer de nossas patrícias elementos sólidos com que a sociedade dispusesse de futuro para atingir a culminância do valor, da estética do espírito." (PARAÍBA, Estado da. EM TORNO... 10 de agosto de 1933, p.11).

Seguindo os passos da FBPF, que tinha como primeiro ponto de seu estatuto a promoção da educação da mulher, enfatizando que não avançaria em qualquer área se antes não lhe fosse dada a educação plena, suas filiais pelo país afora, salvas as particularidades, tinham em comum dois pontos: a luta pelo voto e o direito à educação. Dessa forma, a APPF deixa claro, em sua primeira sessão preparatória que funcionará:

[...] mais ou menos nos moldes da "Federação Brasileira pelo Progresso Feminino" cujos principais fins são: $1^{\circ}$. Promover a educação da mulher e elevar o nível da instrução feminina; $2^{\circ}$. 
Proteger a mãe e a infância; $3^{\circ}$. Obter garantias legislativas para o trabalho feminino; $4^{\circ}$. Auxiliar as boas iniciativas da mulher e orientá-la na escolha de uma profissão. $5^{\circ}$. Estimular o espírito de sociabilidade e de cooperação entre as mulheres e interessá-las pelas questões sociais e de alcance público. (PARAÍBA, Estado da. A FUNDAÇÃO..., 8 de fevereiro de 1933, p. 3 - grifos nossos).

No intuito de desenvolver o seu programa educativo, a APPF propõe como ações iniciais a criação de uma biblioteca, aulas de língua, promoção de sessões literomusicais e criação de núcleos de estudo voltados para questões relativas ao estudo de línguas diversas, de cultura, literatura, geografia e história pátrias, de prendas e economia domésticas, de pintura e música, de cultura física e jogos recreativos, de beneficência, de noções de direito usual e de educação política e social.

A concepção de educação da APPF está condensada em um texto, escrito pela vice-presidente da Associação, intitulado Um leve conceito, que tem como primeira assertiva: "A educação considerada como um fator natural tem por fim a acomodação do indivíduo ao meio em que ele vive." (CUNHA, 1933, p.10). Por essa afirmação, é possível perceber a preocupação da Associação em não polemizar com o estabelecido. Continuando a exposição, o meio moral é posto em relevo como fator que conduz o homem à perfeição, por isso a educação deve ajustar a criança ao seu círculo social. A responsabilidade inicial é dos pais que devem sondar os interesses do filho para saber educá-lo. A ocorrência de erros nessa educação inicial, - isto é, se os pais não fossem bons modelos - terá como consequências falhas no caráter dos filhos, uma vez que a imitação seria a primeira forma de aprendizagem. O educador, por sua vez, também deve ser exemplo para a criança e, não basta apenas a competência técnica e o conhecimento, deve ter o senso aguçado para identificar as más tendências inatas, como também as qualidades, o talento, os dotes, o caráter rígido. Tanto a família quanto o educador, principalmente este, deve combater sentimentos como ingratidão, orgulho, inveja, hipocrisia, que desvirtuam o caráter em formação. Muitos aspectos relacionados à educação, que não serão abordados aqui, são contemplados no desenvolvimento do texto, como a desvalorização do professor e a supervalorização da educação como algo quase sagrado, entre outros.

Vale destacar a importância da Página Feminina ${ }^{3}$ conquistada pela Associação no jornal A União como veículo de divulgação do pensamento das associadas em relação aos mais diversos assuntos. Não só os membros da direção escreviam, mas qualquer sócia poderia se manifestar sobre algum assunto, inclusive havia incentivo constante à escrita feminina e os textos literários eram muito bem acolhidos. 


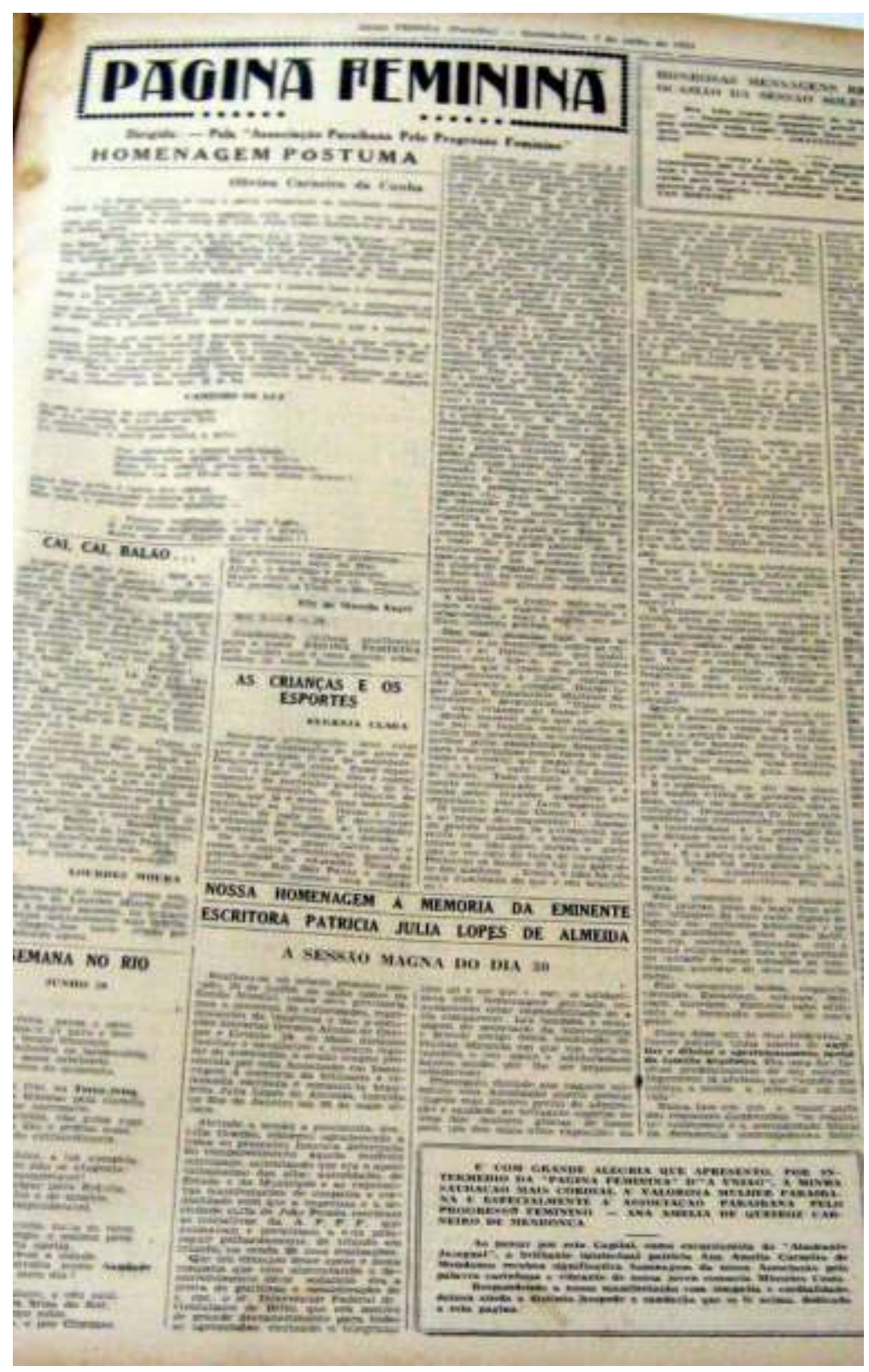

Imagem 1: Fotografia da Página Feminina Fonte: PARAÍBA, Estado da. 5 de julho de 1934, p. 9.

A imagem acima traz um exemplar da Página Feminina na qual podemos perceber que a folha foi dividido para 7 textos diferentes, sendo que a maior parte da página foi ocupado para uma homenagem à escritora brasileira Júlia Lopes de Almeida, falecida a 30 de maio de 1934. O comum é que a Página contemple assuntos diversos que abrangem gêneros textuais distintos: notícias, poemas, novelas, notas, artigos, anúncios, ora assinados por uma sócia, ora por uma convidada, ou sem assinatura nenhuma, neste caso indica ser um texto oriundo da própria direção. Também é frequente encontrar publicações transcritas de outros jornais nacionais, em sua grande maioria, também produzidos por 
mulheres; raramente se localiza um texto de autoria masculina, mas quando isto acontece, trata das questões femininas e reflete a empatia de seu autor com as ideias da Federação Brasileira pelo Progresso Feminino e suas filiais. Observando a Página em seus sete anos de publicação, poucas fotografias aparecem; o que pode ser um indício de que as sócias queriam aproveitar ao máximo o espaço para a publicação da produção escrita das mulheres.

\section{Escritos de/para formação da mulher}

Não faremos aqui uma análise exaustiva dos textos publicados, mas apenas situaremos a importância dos temas abordados pelos mesmos, não apenas como divulgação de ideias, mas como material de formação para as mulheres paraibanas, procurando estabelecer uma classificação temática que realce o caráter educativo dos mesmos, articulado com a proposta inicial apresentada em suas primeiras sessões.

Muitas vezes, os textos publicados na Página Feminina estão acompanhados da informação indicativa do núcleo a que se referem. É comum que um texto esteja associado a mais de um núcleo, o que demonstra a interdisciplinaridade dos temas, mas também um princípio de economia; uma vez que esta associação a mais de um núcleo liberaria também o espaço para a escrita de outros . Observando isso, propomos uma classificação temática inicial; inicial porque é o primeiro, e é possível que outras leituras, nossas ou de outrem, revelem detalhes não contemplados neste momento, que nos façam rever esta análise, alterando-a ou retificando-a. A APPF fez uma classificação por núcleos, o que propomos aqui é agrupar por temas considerando principalmente o título dos textos e uma leitura inicial, quase dinâmica, dos mesmos, portanto não será feita uma análise de seus conteúdos, o que tem sido feito em outras publicações nossas, quando focamos um texto específico ou um conjunto deles que versam sobre uma mesma questão. ${ }^{4}$

Os núcleos propostos pela Associação foram os seguintes: $1^{\circ}$. Literatura e cultura da língua materna; $2^{\circ}$. Brasilidade - geografia e história pátria; $3^{\circ}$. Francês; $4^{\circ}$. Inglês; $5^{\circ}$. Alemão; $6^{\circ}$. Italiano; $7^{\circ}$. Economia doméstica; $8^{\circ}$. Cultura Física; $9^{\circ}$. Prendas domésticas Pintura; $10^{\circ}$. Jogos recreativos - Música; $11^{\circ}$. Beneficência; $12^{\circ}$. Educação Política Social - Noções de Direito Usual.

A classificação temática que ora apresentamos leva em consideração a frequência com que o tema aparece durante a vigência da referida página e parece contemplar os textos publicados.

\section{$1^{\circ}$. Notícias, festas e outros eventos}

Nesse item entram tanto notícias referentes à própria Associação e suas ações, quanto a participação de suas associadas em eventos, visitas de autoridades, publicação de livros etc. Exemplo desse caso, podemos citar: A biblioteca da Associação Paraibana pelo Progresso Feminino (20 ago. 1933); A Barragem - texto de Olivina Carneiro da Cunha sobre a publicação do livro homônimo de Inez Mariz (13 mar. 1938, p.1). Há uma quantidade considerável de textos versando sobre festa, com uma riqueza de detalhes e informações que extrapola o limite da mera notícia. Por exemplo: Festa do verão - Olivina Carneiro da Cunha (19 out. 1933), Baile de máscaras - Beatriz Ribeiro (18 fev. 1934), A festa da Vitória (3 set. 1934). A princípio, ficamos em dúvida se deveríamos considera-las 
simples Notícias, mas pela extensão dos textos, pela riqueza dos detalhes e de informações, consideramos que merecem uma nomeação específica. A organização de festas, com objetivos distintos era uma atividade muito frequente da APPF; era festa para homenagear uma autoridade local; para recepcionar visitante(s), geralmente, mulheres envolvidas nos movimentos feministas ou escritoras nacionais e estrangeiras; festa para angariar fundos para uma associação beneficente; para marcar uma estação do ano etc.

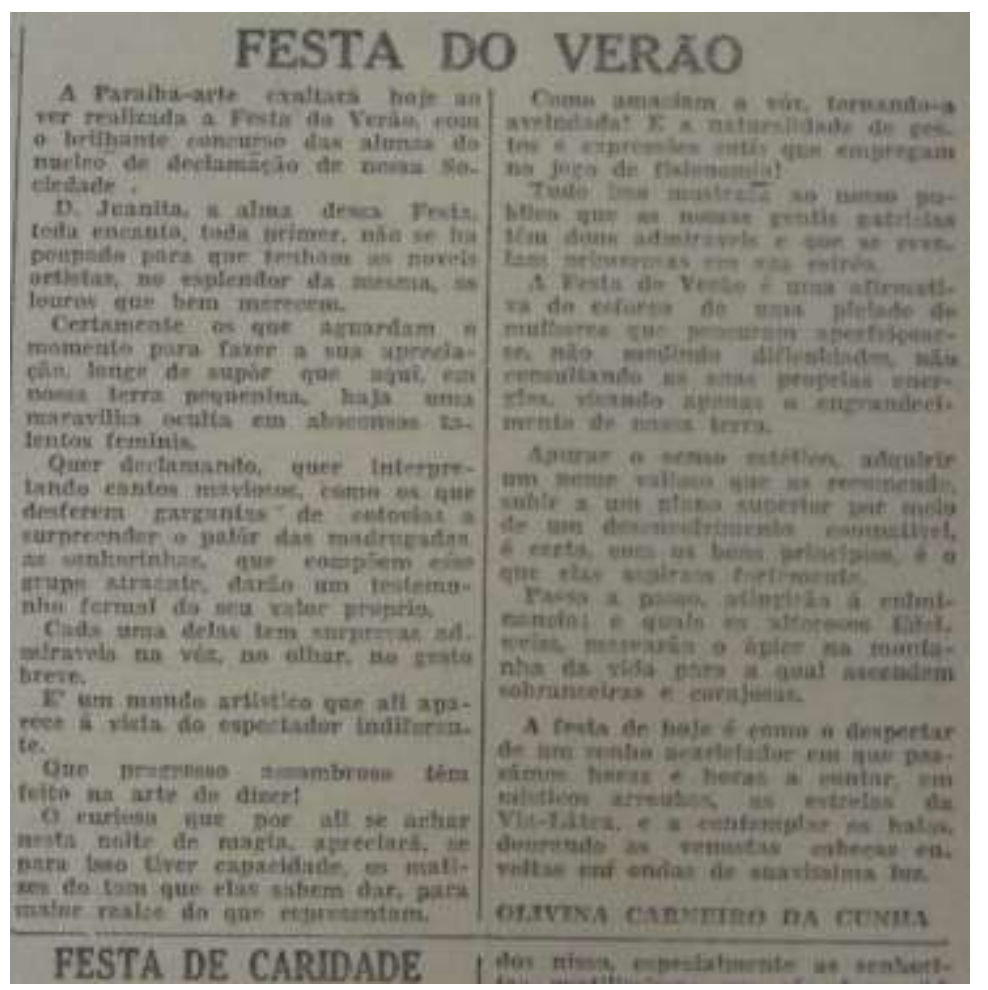

Imagem 2: Recorte da Página Feminina destacando um texto sobre festa Fonte: PARAÍBA, Estado da. 19 de outubro de 1933, p. 4.

Conforme pode ser lido no texto acima, e em outros do mesmo teor, o anúncio da festa, a descrição, a notícia ou relato da mesma são oportunidades utilizadas pela APPF para destacar a importância das ações que a mesma vem desenvolvendo em prol do crescimento intelectual da mulher paraibana.

\section{$2^{\circ}$. Mulher e feminismo}

Pela especificidade da associação, esse tema é bem frequente. Ora é contemplada a mulher segundo as suas funções na sociedade, incluindo o seu papel junto à família; ora o que se destaca é a mulher ligada às lutas feministas. Por exemplo: A mulher paraibana, por Maria Estela Costa (14 set. 1933); Registro da mulher moderna, texto da direção da APPF sobre Bertha Lutz (10 jan. 1934, p.9); O que a mulher tem feito (21 abr. 1934, p.11), A questão do trabalho noturno feminino - de Albertina Correia Lima (15 set. 1935, p 16); Conquistas femininas (26 jul. 1936, p.11); A mulher - Maria Falcone (17 out. 1937, p.2); A influência da mulher moderna - Lilia Guedes (12 jun. 1938, p.1). Esse é um dos temas mais recorrentes na Página Feminina, assinalando a coerência da Página com o órgão que 
representa, a APPF, cujo nascedouro, a FBPF, teve como norte organizador a luta pelos direitos femininos, sob a orientação e coordenação da ativista Bertha Lutz. ${ }^{5}$

\section{$3^{\circ}$. Comportamento, etiqueta e moda}

Nesse tema, enquadram-se textos de núcleos diversos, que podem estar relacionados à Economia doméstica, à Cultura Física, às Prendas domésticas, aos Jogos recreativos. Nos textos aqui agrupados, há uma ênfase ao comportamento tanto da mulher quanto da criança; às vezes aparece resenha ou tradução de obras francesas que versam sobre o assunto. Como exemplo dessa temática, citamos: Brinquedo de roda - de Santinha de Sá (19 out. 1933,); Definição do beijo - Juanita Machado (12 nov. 1933), Questões de etiqueta: o aperto de mão (12 dez. 1933, p. 16) Questões de etiqueta do Savoir - livre et visages mondaines pela Condesse de Genner, em tradução (16 fev. 1934, p.7), As crianças e as festas - de Eugênia Clara (13 maio 1934, p 16), As crianças e a maquilagem Eugênia Clara (19 abr. 1934, p. 9), As crianças e o esportes (5 jul. 1934), Coisas da moda - Albertina Correia Lima (19 fev. 1936).

A presença abundante dessa temática na Pagina Feminina, abordando aspectos vários do comportamento e da conduta feminina e infantil, mostra que embora as mulheres estivessem empenhadas em conseguir direitos e ocupar outros espaços, além do lar, não se descuidavam do que ainda era considerado atribuição sua, cuidar e educar as crianças; bem como davam importância à moda, que era uma outra vertente considerada inerente à vida da mulher. Vestir-se adequadamente ou não era quesito de preocupação cotidiana das mulheres, principalmente das que possuíam as condições culturais, econômicas e de instrução favoráveis, como era o caso das sócias e dirigentes da APPF.

\section{$4^{\circ}$. Beneficência ou assistencialismo (a prática da caridade)}

Esse assunto é muito caro à APPF; desde suas reuniões preparatórias, passando pela definição do seu campo de atuação e de seus núcleos, é dada uma ênfase grande à caridade. Depois, deixa claro que tem intenção de desenvolver ações para combater a mendicância e oferecer um pouco de instrução às moças pobres. Há uma quantidade considerável de textos tratando desse assunto, como: A caridade - de Lilia Guedes (26 nov. 1933), Visão da caridade (18 fev. 1934), Natal dos pobres e das crianças (21 nov. 1935).

\section{$5^{\circ}$. Educação}

É um tema recorrente na Página Feminina, o que é natural já que é preocupação relevante da Associação, conforme foi definido em seu estatuto o seu primeiro artigo. Exemplos são os textos: Escola nova (25 mar. 1934), Valor da educação - Lilia Guedes (25 fev. 1935). Em 10 novembro de 1935, a página é dedicada aos professores e contém textos como: Ação do professor, de Olivina Carneiro da Cunha, Missão social do professor, de Albertina Correia Lima, Mestre, de Analice Caldas, Mestres de hoje, de Alice Azevedo Monteiro. Outros: O cinema e a educação social - Olivina Carneiro da Cunha (10 maio 1936), O magno problema - escrito por Lilia Guedes, sobre o analfabetismo. Pelo título dos textos, já se percebe a amplitude temática da questão, bem como a atualização da discussão empreendida na Página com os aspectos contemporâneos do contexto educacional. 


\section{$6^{\circ}$. Cultura brasileira ou Brasilidade}

A valorização e o interesse pela cultura brasileira, sua geografia e história, bem como suas artes estão bem divulgados na Página feminina. Inclusive, a Associação anuncia seu interesse em elaborar um dicionário corográfico brasileiro, um álbum de monografias e um pequeno museu de geografia e história pátria. Para isso, encaminha a todos os municípios do Brasil uma circular, pedindo informações sobre paisagens, prédios, índios, arte etc. Os textos sobre o assunto podem ser exemplificados por: Conheçamos nossa terra (19 out. 1933), Um mês de arte brasileira - Juanita Machado (24 dez. 1933), As nossas praias e a história - de Olivina Carneiro da Cunha (19 jan. 1936).

\section{$7^{\circ}$. Textos literários}

Dentro dessa categoria incluem-se tanto poemas, quanto crônicas ou prosa poética. Mas a grande predominância é do poema. Além da produção das associadas, é comum aparecerem poemas de escritoras de outros estados. Os poemas contemplam assuntos como: amor, amizade, caridade, belezas naturais, saudade, solidão, a mulher. É o que nos indicam alguns títulos: Confidências - Olivina Carneiro da Cunha (6 fev. 1934), Evocação - de Cotinha Carneiro da Cunha (25 mar. 1934), A poesia das manhãs de abril - Lilia Guedes (21 abr. 1934), Flores, estrelas e mulheres - Isabel Iracema Feijó da Silveira (1 Maio 1937).

Sabe-se que a escrita de textos literários, durante muito tempo, foi bastante incentivada às mulheres, primeiro porque tinha um caráter de distração, futilidade ou atividade sem muita seriedade e bastante propícia às "sensíveis" senhoritas; em segundo lugar, os assuntos sérios como política, economia, história cabiam aos homens, considerados mais capazes intelectualmente. Todavia, nem todas as mulheres tinham/têm acesso à literatura, como um bem cultural rico e pertinente para se conhecer o ser humano e a sociedade. Se esse espaço à literatura foi sendo aberto pela mulher, esteve sempre associado a uma outra conquista, o direito de estudar, de alfabetizar-se, que traria como ganho a tomada da palavra e a levaria, gradativamente, a sair do silêncio e da invisibilidade impostos por séculos. Perrot (2005, p. 13) diz bem sobre essa questão:

A literatura, esta epopeia do coração e da família, é felizmente, infinitamente mais rica. Ela nos fala do cotidiano e dos "estados da mulher", inclusive pelas mulheres que nela se intrometeram. Pois a escuta das "palavras da mulher" depende de seu acesso aos meios de expressão: o gesto, a fala, a escrita. O uso desta última, essencial, repousa sobre o grau de alfabetização e o tipo de escrita que lhes é concedido. Inicialmente isoladas na escrita privada e familiar, autorizadas a formas específicas de escrita pública (educação, caridade, cozinha, etiqueta...), elas se apropriaram progressivamente de todos os campos da comunicação - o jornalismo por exemplo - e da criação: poesia, romance sobretudo, história às vezes, ciência e filosofia mais dificilmente. Debates e combates balizam estas travessias de uma fronteira que tende a se reconstituir, mudando de lugar.

A mulher apropriou-se da escrita para dizer seus conhecimentos, suas experiências, suas emoções e opiniões, variando incessantemente o modo, o como, o onde e o para quê 
escrever.

A classificação apresentada não tem a pretensão de ser absoluta e definitiva, mas procurou abranger a diversidade textual produzida no interior da APPF; como também os textos citados são apenas amostras, já que não seria possível citá-los todos aqui.

A Página Feminina funcionou com uma frequência regular - a proposta era quinzenal - nos dois primeiros anos, 1933 e 1934. A partir do ano de 1935, percebe-se que a publicação vai saindo num espaço de tempo maior do que 15 dias, mas até 1938 ainda é significativa, escasseando em 1939, quando desaparece sem explicação. Embora ainda não tenhamos material suficiente sobre a década de 1940, observamos que a partir daí vão sendo publicados textos isolados de mulheres pertencentes aos quadros da Associação. Em 1941, as associadas da APPF aparecem como notícia nas páginas do jornal e no final do segundo semestre o espaço da Página Feminina é ocupado por uma seção intitulada Do lar e da mulher, no qual são veiculados textos escritos por outras mulheres que parecem não ter vínculo com a Associação; há textos também de autoria masculina. Mas isso é assunto para outro texto.

\section{Considerações finais}

A Página Feminina foi um espaço importante para a Associação Paraibana pelo Progresso Feminino. Provavelmente a conquista desse espaço deveu-se à comunhão de ideias políticas entre suas associadas e a direção do jornal $A$ União. Como também a posição clara, inicial, da Associação, de que não havia intuito de polemizar com as instituições responsáveis pela ordem e organização da sociedade naquele momento, como a igreja, o Estado e a imprensa.

É possível observar, nos textos publicados nos primeiros meses, um tom comportado e voltado muito mais para as ações desenvolvidas, destinadas, muitas vezes, à beneficência e à homenagem a figuras ilustres da sociedade, ou reflexões sobre aspectos ligados à cultura brasileira em geral e aos comportamentos adequados. Na continuação, percebe-se uma quantidade de textos expressiva voltada para a questão do feminismo, dos novos papéis que a mulher deve exercer, do questionamento das posições restritivas em relação aos direitos da mulher. Torna-se frequente também a divulgação das ações da FBPF e a realização de eventos feministas internacionais. Estaria a APPF saindo de um "feminismo elegante" (MACEDO, 2000), comportado para uma ação mais combatente?

Através de uma temática variada, na maioria das vezes relacionada a um núcleo ou mais de sua composição, os textos publicados pela Página Feminina, além de contribuírem para a divulgação das ideias norteadoras da Associação, dos debates que circulavam pelo país afora sobre os direitos da mulher, foram, sem sombra de dúvida, instrumento de formação, não só para suas associadas, mas, também para as mulheres que naquele momento tinham acesso a esse veículo de comunicação.

Importante destacar também a função de espaço de escrita feminina exercida pela Página, quando se sabe que durante muito tempo essa prática esteve circunscrita aos recônditos da casa, à escrita familiar autorizada, aos escritos de si mantidos sob sigilo e censura, às escritas ordinárias, sem visibilidade e na maioria das vezes sem alcance temporal além daquele em que foi produzido, o que tem se constituído como fator que dificulta a escrita da história das mulheres. 
A leitura realizada permite afirmar que a APPF usou o espaço no órgão oficial da imprensa paraibana tanto na propagação de suas ações quanto no fomento da educação das mulheres paraibanas, no momento em que as mesmas reivindicavam direitos e buscavam visibilidade. Os textos publicados fazem referência constante a uma variedade de assuntos educacionais do contexto destacado, voltados não apenas para a educação da mulher, mas também para a educação de outros sujeitos.

\section{Referências}

AGUIAR, Wellington. João Pessoa o reformador - transcrição das verdadeiras cartas achadas no escritório de João Dantas. João Pessoa: Ideia, 2005.

CHARTIER, Roger. Os desafios da escrita. Tradução Fúlvia M. L. Moretto. São Paulo: Editora Unesp, 2002.

CUNHA, Olivina O. C. da. Um leve conceito. PARAÍBA, Estado da. Jornal A União. João Pessoa, 17 de setembro de 1933, p. 10.

DAUPHIN, Cecile. Mulheres sós. In: História das mulheres no Ocidente - o século XIX. v. 4. Direção de Geneviève Fraisse e Michelle Perrot. Porto: Afrontamentos, 1991, p. 477 495.

ELIAS, Norbert. Introdução à Sociologia. Tradução de Maria Luiza Ribeiro Ferreira Lisboa, Portugal: Edições 70, 1970.

PARAÍBA, Estado da. EM TORNO DE UMA IDÉIA. Jornal A União. João Pessoa, 20 de agosto de 1933, p.11.

JOFFILY, José. Anayde Beiriz: paixão e morte na Revolução de 30. Rio de Janeiro: Companhia Brasileira de Artes Gráficas, 1980.

MACEDO, Elza D. V. Uma luta justa... elegante: os feminismo conflitantes de Bertha Lutz e Maria Lacerda Moura na década de 1920. Gênero, v. 3, n. 2, Eduff.

MELLO, José Octávio de Arruda. Exposição e debates do II SBCB: João Pessoa, a Paraíba e a Revolução de 30. João Pessoa: Secretaria de Educação e Cultura do Estado da Paraíba, 1979.

MACHADO, Juanita B. Pela elevação mental da mulher paraibana. PARAÍBA, Estado da. Jornal A União. João Pessoa, $1^{\circ}$ de junho de 1933, p.3

MACHADO, Juanita B. Pela elevação mental da mulher paraibana. PARAÍBA, Estado da. Jornal A União. João Pessoa, 25 junho de 1933, p.1.

MACHADO, Charliton José dos Santos; NUNES, Maria Lúcia da Silva. O feminismo paraibano: Associação Paraibana pelo Progresso Feminino (APPF) - 1930. (Orgs.) Gênero \& Sexualidade: perspectivas em debate. João Pessoa: Editora Universitária, 2007. p. 193-207.

NUNES, Maria Lúcia da Silva. A imprensa paraibana e os direitos da mulher: textos publicados no jornal A União em 1920. SCOCUGLIA, Afonso Celso; MACHADO, Charliton José dos Santos (Orgs.). Pesquisa e historiografia da educação brasileira. Campinas, SP: Autores Associados, 2006. p.115-132. 
; CAVALCANTE, Elane Candido; VILAR, Adriana Marcineiro. De mestre a "mendigo de gravata": educadoras paraibanas e suas concepções de docência (1935). FIALHO, Lia M. F.; ALMEIDA, Gildênia M. de A.; CASTRO, Edilson Silva (orgs.). Pesquisas educacionais biográficas. Fortaleza: Edições UFC, 2014, p. 59-78.

Casamento: um (bom) negócio! - uma leitura do romance São Bernardo. MACHADO, Charliton J. dos S.; NUNES, Maria Lúcia da S. (orgs.). Gênero \& Sexualidade: perspectivas em debate. João Pessoa: editora Universitária, 2007, p. 283-296.

PARAÍBA, Estado da. A BRILHANTE FESTA DA "ASSOCIAÇÃO PARAIBANA PELO PROGRESSO FEMININO” EM HOMENAGEM AO INTERVENTOR GRATULIANO DE BRITO, AO CÔNEGO MATHIAS FREIRE E À IMPRENSA. Jornal A União. João Pessoa, 25 de julho de 1933, p1.

PARAÍBA, Estado da. A FUNDAÇÃO NESTA CAPITAL DE UMA ASSOCIAÇÃO FEMININA. Jornal A União. João Pessoa, 8 de fevereiro 1933.

PARAÍBA, Estado da. ASSOCIAÇÃO PARAIBANA PELO PROGRESSO FEMININO. Jornal A União. João Pessoa, 5 de abril de 1933, p.8.

PARAÍBA, Estado da. ASSOCIAÇÃO PARAIBANA PELO PROGRESSO FEMININO. Jornal A União. João Pessoa, 30 junho de 1933, p. 4.

PARAÍBA, Estado da. FESTA DO VERÃO. Jornal A União. João Pessoa, 19 de outubro de 1933, p. 4.

PARAÍBA, Estado da. Jornal A União. João Pessoa, 25 de janeiro de 1930, p.1.

PARAÍBA, Estado da. Jornal A União. João Pessoa, 16 de maio de 1930, p.5.

PARAÍBA, Estado da. Jornal A União. João Pessoa, 20 de novembro de 1930, p.1.

PARAÍBA, Estado da. Página Feminina. Jornal A União. João Pessoa, 5 de julho de 1934.

PERROT, Michelle. As mulheres ou os silêncios da história. Tradução Viviane Ribeiro. Bauru, SP: EDUSC, 2005.

SOIHET, Raquel. A pedagogia do espaço público pelas mulheres e a militância feminista de Bertha Lutz. Revista Brasileira de Educação, Campinas, Autores Associados, n. 15, p. 97-117, set/out/nov/dez. 2000.

A construção do espaço público. PINSKY, Carla B.; PEDRO, Joana M. (Orgs.) Nova História das Mulheres. São Paulo: Contexto, 2012, p. 218-237.

VIEIRA, Eudésia. A mulher e o Progresso. PARAÍBA, Estado da. Jornal A União. João Pessoa, 30 de setembro de 1932, p. 4. 


\section{Notas}

${ }^{1}$ Professora da graduação e do programa de pós- graduação em educação/ PPGE- UFPB/ Universidade Federal da Paraíba. mlsnunesml@gmail.com

${ }^{2}$ Professor da graduação e do programa de pós-graduação em educação/ PPGE- UFPB/Universidade Federal da Paraíba charlitonlara@ yahoo.com.br

${ }^{3} \mathrm{O}$ acesso inicial aos textos da Página Feminina deu-se por ocasião da escrita do texto Associação Paraibana pelo Progresso Feminino e sua contribuição à educação da mulher paraibana, MACHADO, C. J. S. ; NUNES, M. L. S. AFIRSE - IV Colóquio Nacional - Epistemologia das Ciências da Educação, 2007, Natal/RN. Anais do IV Colóquio Nacional - Epistemologia das Ciências da Educação. Natal/RN: Editora da UFRN, 2007. Posteriormente, com a orientação da dissertação Associação Paraibana pelo Progresso Feminino: as contribuições educacionais para a mulher paraibana (1933 a 1939), de Verônica de Souza Fragoso, teve-se acesso a todos os textos publicados pela APPF na Página Feminina, do jornal A União de 1933 a 1939.

${ }^{4}$ Exemplo disso é o texto De mestre a "mendigo de gravata": educadoras paraibanas e suas concepções de docência (1935) (NUNES; CAVALCANTE e VILAR, 2014), no qual analisamos textos publicados por sócias da APPF, na Página Feminina, em outubro de 1935, em que as mesmas discorrem sobre o papel do/a professor/a, as dificuldades enfrentadas no cotidiano docente, a desvalorização do trabalho, entre outras questões.

${ }^{5}$ Bertha Lutz é, realmente, um nome que sobressai na luta pelos direitos femininos na primeira metade do século XX; além da criação da Federação Brasileira pelo Progresso Feminino, fundou ou integrou outras associações como a Aliança Brasileira pelo Sufrágio Feminino e a União Universitária Feminina, esta última posteriormente denominada de Associação Brasileira de Mulheres Universitárias. (SOIHET, 2012, p.234).

Recebido em fevereiro-14

Aprovado em março-14 